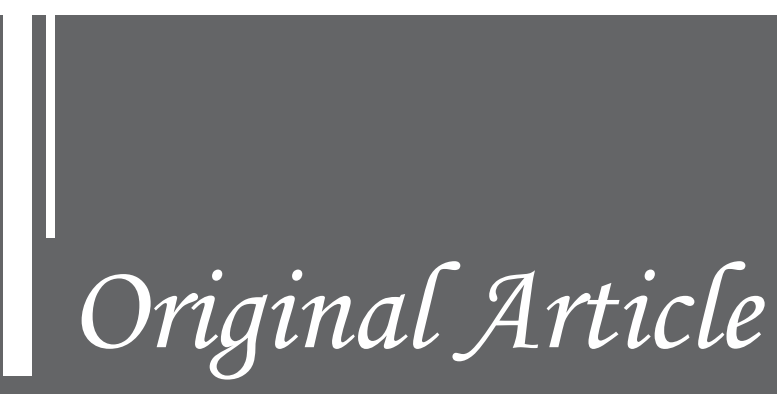

\title{
ASSESSMENT OF KNOWLEDGE REGARDING BREASTFEEDING AMONG PREGNANT WOMEN/MOTHERS VISITING TERTIARY CARE HOSPITAL IN PUNJAB PROVINCE OF PAKISTAN
}

\author{
Rabia Javed ${ }^{1}$, kauser Aftab Khan ${ }^{2}$, Ujala Saleem ${ }^{3}$, Maryam Nawaz ${ }^{4}$, \\ Samina Asghar ${ }^{5}$, Bilal Ahmad
}

${ }^{1}$ Demonstrator, Department of Community Medicine, Gujranwala Medical College, Gujranwala. ${ }^{2}$ Assistant Professor, Department of Community Medicine, Gujranwala Medical College, Gujranwala.

${ }^{3}$ Ex-House Officer, Sir Ganga Ram Hospital, Lahore.

${ }^{4}$ PGR Internal Medicine, Gov.Teaching Hospital Shahdra/Sir Ganga Ram Hospital, Lahore

${ }^{5}$ Professor/Head , Department of Obstetrics and Gynaecology, Gujranwala Medical College/DHQ-Teaching Hospital, Gujranwala.

${ }^{6}$ Classified Medical Specialist, Military Hospital, Rawalpindi

Corresponding Author: Rabia Javed, Email: rjc919@gmail.com

\begin{abstract}
Background: Breastfeeding is essential for an individual's fundamental health starting from birth till the later stages of life. There is sound evidence for the positive impact of breastfeeding on the health of children, mothers and the community as a whole. A heavy percentage of infants are still devoid of optimal breastfeeding in Pakistan. One of the major factors contributing to this is reduced knowledge about benefits and practice of breastfeeding among mothers. The present research was carried out to assess the knowledge of women regarding breastfeeding.

Methods: This was a cross-sectional study carried out in Sir Ganga Ram Hospital in the capital city of Punjab from the 1st to 7th of August 2017 during the world breastfeeding week as part of breastfeeding awareness campaign. 200 women attending the obstetrical and pediatric outpatient departments were randomly selected. Following informed consent, a self-designed 5-item questionnaire was handed over to pregnant women and mothers and the completed questionnaires were collected by the investigator. The data was entered and analyzed using SPSS version 22 .

Results: 200 pregnant women completely filled the questionnaire. Only $12.5 \%$ knew that breast milk should be the first intake of the babies while $33 \%$ knew that it should be initiated in the first hour of birth. $23 \%$ knew that exclusive breastfeeding should be continued for up to 6 months. $44 \%$ said that babies should be breastfed for up to 10 to 20 times day and only $29 \%$ knew that only breast milk should be given to the babies during the period of exclusive breastfeeding. The total knowledge score calculated was $17.14+-2.34$ and was found to be positively related to age of the mother, her educational status and the number of children.

Conclusion: There is good knowledge about breastfeeding amongst pregnant women and mothers visiting the outpatient department of Sir Ganga Ram Hospital, Lahore. There is a need of creating awareness amongst them through workshops, seminars and awareness campaigns.
\end{abstract}

Keywords: Mother and child nutrition, exclusive breast feeding, low and middle income countries 


\section{Background}

Breastfeeding is essential for an individual's fundamental health starting from birth till the later stages of life(1). It is essential to start breastfeeding the newborn at the right time and for the required duration of period. According to WHO breastfeeding should be initiated in the first hour after birth (2). It also recommends exclusive breastfeeding for up to 6 months followed by additional feeding for the next 18 months (3). Following the optimal breastfeeding practices has many advantages. There is sound evidence for the positive impact of breastfeeding on the health of children, mothers and the community as a whole (4). The main benefits of breastfeeding to mothers include decreased maternal postpartum bleeding, decreased risk of certain types of cancer (including ovarian, endometrial) and also osteoporosis (5).

Bottle feeding, the alternative to breastfeeding, is a major factor in the causation of late neonatal sepsis (6). Availability of formula milk has increased infant mortality by $9.4 / 1000$ births. The major reason attributed to it is the use of undistilled water, which acts as a vector for transmission of waterborne pathogens to infants (7)

UNICEF has published guidelines listing '10 steps for optimal breastfeeding ' that should be followed by every such facility that provides Mother Child Healthcare (MCHC) services to the mothers and newborn child $(8,9)$.The main aim of these guidelines is to provide informational care to the mother regarding maternal problems relating to breastfeeding. Despite all efforts, the percentage of breastfeeding is alarmingly low. Major determinants of this diminishing percentage include maternal employment status, maternal education, parity, antenatal visits and health provider support (10-12).

The percentage of breastfed infants in Pakistan is dangerously low (13). One of the major factors contributing to this decreased frequency of breastfeeding in Pakistan is due to reduced knowledge of mothers (14).There is a need to inquire about the level of understanding and knowledge regarding this major issue amongst the female population of the country. The present research, therefore, was carried out to assess the knowledge of women (especially pregnant women and mothers) regarding breastfeeding who are attending the outpatient department of Sir Ganga Ram Hospital, a tertiary care hospital in the capital city of Punjab province of Pakistan.

\section{Methodology}

The research was approved by the ethical review board of the institute This was a one week observational descriptive cross-sectional study carried out in Sir Ganga Ram Hospital in the capital city of Punjab from the 1st to 7th of August 2018 during the world breastfeeding week as part of breastfeeding awareness campaign. A sample size of 200 was calculated for the study with an anticipated non-response rate of $10 \%$ and $7.5 \%$ margin of error. A self-designed 5-item questionnaire was used for data collection which was validated by 3 experts including 2 pediatricians and one gynecologist. A pilot study was done on 10 women and the Cronbach's ? for internal consistency was 0.70 . Women attending the obstetrical and pediatric outpatient departments were randomly selected by simple randomization technique. Following informed consent, the questionnaire was handed over to pregnant women and mothers and the completed questionnaires were collected by the investigator. The data was entered and analyzed using SPSS version (22). Descriptive analysis was used for the individual responses to each question to be expressed as frequencies and percentages. The total knowledge score was 25, 5 marks for each correct answer. Score less than 15 was considered "poor", 15 to 20 as "good" and (21-25) as "excellent" score. Chi-square test was used to find out the correlation between different demographic variables and the total knowledge score. P-value was set at 0.05 . Mean and standard deviation was calculated for the total knowledge score.

Results

200 pregnant women completely filed the questionnaire. The demographic variables are given in the Table No. 1 .
Table 1: Demographic Variables

\begin{tabular}{|c|c|c|c|c|}
\hline \multicolumn{2}{|c|}{ Demographic Variables } & Number & Average & P-Value \\
\hline \multirow{4}{*}{ Age } & $<20 y e a r s$ & $23(11.5 \%)$ & $16.34+-5.21$ & \multirow{4}{*}{0.043} \\
\hline & 21-25years & $72(36 \%)$ & $17.56+-4.90$ & \\
\hline & 26-30years & $65(32 \%)$ & $15.70+-3.81$ & \\
\hline & $>30$ years & $40(20 \%)$ & $18.98+-3.98$ & \\
\hline \multirow{4}{*}{ Educational Status } & Uneducated & $77(38.5 \%)$ & $14.09+-4.91$ & \multirow{4}{*}{0.021} \\
\hline & Matric or equivalent & $84(42 \%)$ & $17.98+-5.43$ & \\
\hline & College or Equivalent & $32(16 \%)$ & $19.71+-2.45$ & \\
\hline & $\begin{array}{c}\text { University or } \\
\text { Equivalent }\end{array}$ & $7(3.5 \%)$ & $19.64+-3.08$ & \\
\hline \multirow{2}{*}{$\begin{array}{l}\text { Employment } \\
\text { Status }\end{array}$} & Unemployed & $157(78.5 \%)$ & $17.90+-4.38$ & \multirow[b]{2}{*}{0.091} \\
\hline & Employed & $43(21 \%)$ & $16.73+-3.07$ & \\
\hline \multirow{5}{*}{$\begin{array}{l}\text { Number of } \\
\text { Children }\end{array}$} & 1 & $64(32 \%)$ & $16.98+-3.90$ & \multirow{5}{*}{0.041} \\
\hline & 2 & $72(36 \%)$ & $16.09+-4.32$ & \\
\hline & 3 & $32(16 \%)$ & $19.32+-3.90$ & \\
\hline & 4 & $24(12 \%)$ & $18.90+-4.98$ & \\
\hline & . & $8(4 \%)$ & $18.23+-4.12$ & \\
\hline \multirow{5}{*}{$\begin{array}{l}\text { Age of Last Born } \\
\text { Child }\end{array}$} & $0-1 / 2$ year & $47(23.5 \%)$ & $15.96+-6.09$ & \multirow{5}{*}{0.076} \\
\hline & $1 / 2-1$ Year & $52(26 \%)$ & $16.91+-3.10$ & \\
\hline & $1-1 \frac{1}{2}$ year & $32(16 \%)$ & $16.75+-4.98$ & \\
\hline & $1 \frac{1}{2}-2$ year & $40(20 \%)$ & $17.01+-4.21$ & \\
\hline & 2 year & $29(14.5 \%)$ & $17.32+-3.23$ & \\
\hline
\end{tabular}

Only $12.5 \%$ knew that breast milk should be the first intake of the babies while $33 \%$ knew that it should be initiated in the first hour of birth. $23 \%$ knew that exclusive breastfeeding should be continued for up to 6 months. $44 \%$ said that babies should be breastfed for up to 10 to 20 times day and only $29 \%$ knew that only breast milk should be given to the babies during the period of exclusive breastfeeding. (Table No.2) Table 2: Responses of the Participants

\begin{tabular}{|c|c|c|}
\hline Question & Options & Response \\
\hline \multirow{3}{*}{$\begin{array}{c}\text { What should be the first intake of body } \\
\text { after birth? }\end{array}$} & Honey & $114(57 \%)$ \\
\cline { 2 - 3 } & Crushed date & $61(30.5 \%)$ \\
\cline { 2 - 3 } & Brest Milk & $25(12.5 \%)$ \\
\hline \multirow{3}{*}{$\begin{array}{c}\text { How long after delivery breastfeeding } \\
\text { should be incited? }\end{array}$} & Within 1 hour & $66(33 \%)$ \\
\cline { 2 - 3 } & After 1-6 hour & $102(51 \%)$ \\
\cline { 2 - 3 } $\begin{array}{c}\text { What should be the duration of } \\
\text { exclusive breastfeeding? }\end{array}$ & After 6-12 hour & $32(16 \%)$ \\
\cline { 2 - 3 } & Upto 4 month & $134(67 \%)$ \\
\cline { 2 - 3 } What should be the frequency of \\
breastfeeding in a day? & Upto 6 month & $46(23 \%)$ \\
\cline { 2 - 3 } & Upto 8 month & $20(10 \%)$ \\
\cline { 2 - 3 } & 6-8 times a day & $40(20 \%)$ \\
\cline { 2 - 3 } What other liquids should be given & -10 times a day & $72(36 \%)$ \\
\cline { 2 - 3 } during exclusive breastfeeding? & $10-12$ times a day & $88(44 \%)$ \\
\cline { 2 - 3 } & Plain water & $62(31 \%)$ \\
\cline { 2 - 3 } & Gripe water & $84(42 \%)$ \\
\hline
\end{tabular}

The average knowledge score calculated was 17.14+-2.34 which falls in category of "Good Knowledge". The percentage distribution of the knowledge category is given in table 3 .

Table 3: Knowledge Category

\begin{tabular}{|c|c|c|}
\hline Category & $\mathbf{n}$ & Percentage \\
\hline Poor Knowledge & $85 / 200$ & $42.5 \%$ \\
\hline Good Knowledge & $87 / 200$ & $43.5 \%$ \\
\hline Excellent Knowledge & $28 / 200$ & $14 \%$ \\
\hline
\end{tabular}

\section{Discussion}

Breastfeeding is a key element to ensure optimum health to the newborn infant26. WHO has issued guidelines to ensure optimal breastfeeding 13. Organizations to spread awareness of the merits of breastfeeding, World breastfeeding week is celebrated in the first week of August under the umbrella of World Health Organization, United Nations 15. Despite all these efforts, very low percentage of children are optimally breastfed and most of them are bottle fed. This is mainly attributed to decrease maternal knowledge about the merits of breastfeeding 16,17. Better knowledge of the women leads to better attitudes and improved practices among them. This leads to malpractice among mothers, which leads to poor health of the children and decreased immunity leading to gastrointestinal and respiratory tract infections $7,8,12$. Therefor it is vital to assess knowledge of the mothers in this domain. 
The knowledge of the mothers attending Outpatient Department of Sir Ganga Ram Hospital was assessed by conducting this research. Breastfeeding should be the first feed of the infant after birth. But there is a wrong concept in the Pakistani culture of giving the baby prelacteal feed in the form of dates, honey, sweet water etc. To assess the knowledge regarding this issue, the participant were investigated. According to our research, approximately $25 / 200(12.5 \%)$ of the population were well aware of breast milk being the first food of choice after birth. More than half of the population i.e., 114 out of $200(57 \%)$ believed that honey should be the child's first feed. 61 women out of a total of $200(30.5 \%)$ believed that the infants should be given crushed dated as their initial feed. Our results are comparable to a local study conducted in Mayo Hospital, Lahore, where $67 \%$ of primigravida mothers offered prelacteal feeds to their babies with mostly included honey, 'ghutti', 'araqi', gripe water, sugar water and plain water (18). In contrary to that, Esayas Aydiko Amele et al showed a prevalence of prelacteal feed to be only $20.6 \%$, much less than that seen in our study and the most common item used was plain water. The positive predictors related to pre-lacteal feeding practice were living with joint family, Lack of breastfeeding counseling and mothers who avoid colostrum (19).

On assessing the knowledge regarding initiation of breastfeeding, only a third (66/200) correctly knew that breastfeeding should be initiated in the first hour after birth. Half of the population thought that it should be initiated 1-6 hours after birth, while 16\% said that it can be started 6-12 hours after birth. A slightly higher percentage (46.6\%) of the women were aware an therefore practiced initiating breastfeeding within the first hour of birth in a study conducted in the kingdom of Saudi Arabia. this early initiation was seen to be associated with the mode of delivery and the educational level of the mother (20). Early initiation of breastfeeding is very vital for the child's health and life expectancy. According to research, initiating breastfeeding at the right time has the potential to reduce neonatal mortality by $22 \%$ (21).

When asked about the right duration of exclusive breastfeeding, only about $23 \%(46 / 200)$ knew that exclusive breastfeeding should be continued for good 6 months following birth. $67 \%$ and $10 \%$ of the participants wrongly assessed that it should be continued for upto 4 months and 8 months. Exclusive breastfeeding for around 6 months facilitates the intake of a healthier diet in late childhood (22).WHO recommends exclusive breastfeeding for a duration of 6months (23). No more than $35 \%$ of infants worldwide are exclusively breast fed during the first 4 months of life 3, (24). Complementary feed should be initiated no earlier than the beginning of 5 th month and no later than the beginning of 7th month (25). The complementary food must include the food items to meet the nutritional requirement of the children (26). HN Sarwar et al found significant connection between the optimal duration of exclusive breastfeeding and the place of residence, maternal age, mode of delivery and the financial status of the family (27).

The majority of participants were unaware of the frequency of breastfeeding in a day. $44 \%(88 / 200)$ women knew that the frequency of breastfeeding should be $10-12$ times a day. $56 \%$ of the participants incorrectly answered, $20 \%$ responded 6-8 times while $36 \%$ responded 8-10 times. Mohsin SS et al gave similar results, however, it was seen that there was a gradual decline in this frequency with increasing age of the baby and the time of initiation of complementary feed 12. Optimal frequency of breastfeeding is associated with greater gestational age, early physical contact and breastfeeding favorable attitudes (28).

Lastly, the research participants were asked about the addition of any other liquid along with breast milk during the duration of exclusive breastfeeding. Only a quarter of the population (27\%) knew that only breast milk should be given while $73 \%$ thought that plain water and gripe water can be added. Habibi et al showed that $30.4 \%$ of mothers attending the health centers in Casablanca practices introduction of weaning before 6 months and $66.5 \%$ at 6 months (27).

Overall, the knowledge regarding breast feeding among the women was good with a score of $17.14+-2.34$. There was positive correlation between the total knowledge score and the age, educational status and the total number of children while no association was found when cross tabulated with employment status and age of last born child. Hamza L. et al revealed that most mothers showed neutral knowledge level on breastfeeding as well. The average score of $10.83 \pm 2.77, \mathrm{M} \pm \mathrm{SD}$ for the knowledge section of the questionnaire used (29).Another similar study also demonstrated that mothers have good knowledge on breast feeding (12.05 $\pm 1.74, \mathrm{M} \pm \mathrm{SD}) 30$. In Mohsin SS et al, the knowledge regarding breast feeding was high 10 . The factors as having more than one child, spontaneous vaginal delivery, and having an educated life partner were seen to be related to higher breastfeeding awareness and better attitudes and practices subsequently $(31,32)$.

The limitation of study was that it didn't assess the attitude and practices of women regarding breastfeeding which is important. The association of the individual items of the knowledge questionnaire with the demographic variables was not calculated which was also one of the limitations of our study. Future studies should focus on these shortcomings.

\section{Conclusion}

There is good knowledge about breastfeeding amongst pregnant women and mothers visiting the outpatient department of Sir Ganga Ram Hospital, Lahore. There is a need of creating awareness amongst them through workshops, seminars and awareness campaigns.

Better knowledge the mothers regarding breastfeeding plays a major role in the breastfeeding process. Therefore, it is crucial to ensure provision of proper antenatal and early postpartum education and counselling regarding breastfeeding to improve the knowledge, attitudes and practices of the mothers.

References

1. Munn AC, Newman SD, Mueller M, Phillips SM, Taylor $\mathrm{SN}$. The impact in the United States of the baby-friendly hospital initiative on early infant health and breastfeeding outcomes. Breastfeeding Medicine. 2016 Jun 1;11(5):22230 .

2. Khan J, Vesel L, Bahl R, Martines JC. Timing of breastfeeding initiation and exclusivity of breastfeeding during the first month of life: effects on neonatal mortality and morbidity-a systematic review and meta-analysis Maternal and child health journal. 2015 Mar 1;19(3):46879.

3. global strategy for infant and young child feeding 2017 global strategy for infant and young child feeding 2017

4. Rollins NC, Bhandari N, Hajeebhoy N, Horton S, Lutter CK, Martines JC, Piwoz EG, Richter LM, Victora CG, Group TL. Why invest, and what it will take to improve breastfeeding practices?. The Lancet. 2016 Jan 30;387(10017):491-504.

5. Shamir R. The benefits of breast feeding. InProtein in Neonatal and Infant Nutrition: Recent Updates 2016 (Vol. 86, pp. 67-76). Karger Publishers

6. Goel A, Murmu SK, Shah S, Chawla GS. Role of cultural practices in neonatal sepsis. Int J Med Sci Public Health. 2015 May 1;4(5):680-3.

7. Jan H, Burki F, Ahmad S. Comparison Of Late Neonatal Sepsis In Breast Fed And Bottle Fed Infants Admitted To Khyber Teaching Hospital, Peshawar, Pakistan. Pjhs. 2017 Jan; $1(01): 2$.

8. Labbok MH, Taylor EC, Nickel NC. Implementing the ten steps to successful breastfeeding in multiple hospitals serving low-wealth patients in the US: innovative research design and baseline findings. International breastfeeding journal. $2013 \mathrm{Dec} ; 8(1): 5$.

9. Protecting, Promoting and Supporting Breastfeeding: The Special Role of Maternity Services, a joint WHO/UNICEF statement published by the World Health Organization.

10. Mohsin SS, Shaikh AS, Shaikh R, Haider N, Parkash A. Knowledge attitude and practices of mothers regarding complementary feeding. Journal of Dow University of Health Sciences. 2014 Apr 10;8(1).

11. Joshi PC, Angdembe MR, Das SK, Ahmed S, Faruque AS Ahmed T. Prevalence of exclusive breastfeeding and associated factors among mothers in rural Bangladesh: a cross-sectional study. International breastfeeding journal. 2014 May;9(1):7.Jan H, Burki F,

12. Bich TH, Cuong NM. Changes in knowledge, attitude and involvement of fathers in supporting exclusive breastfeeding: a community-based intervention study in a rural area of Vietnam. International journal of public health. 2017 Feb 1;62(1):17-26.

13. https://data.unicef.org/country/pak/ 
14. Zakar R, Zakar MZ, Zaheer L, Fischer F. Exploring parental perceptions and knowledge regarding breastfeeding practices in Rajanpur, Punjab Province, Pakistan. International breastfeeding journal. 2018 Dec;13(1):24.

15. https://worldbreastfeedingweek.org/

16. Wambach K, Spencer B. Breastfeeding and human lactation. Jones \& Bartlett Publishers; 2019 Sep 2.

17. Demirchyan A, Melkom Melkomian D. Main Barriers to Optimal Breastfeeding Practices in Armenia: A Qualitative Study. Journal of Human Lactation. 2019 Jun 20:0890334419858968.

18. Younus M, Saleem A, Ijaz SF. Prelacteal Feeding Practices among Primigravida Mothers. Age. 2018 Jan 1;25(62):62.

19. Amele EA, wondimeneh Demissie B, Desta KW, Woldemariam EB. Prelacteal feeding practice and its associated factors among mothers of children age less than 24 months old in Southern Ethiopia. Italian journal of pediatrics. 2019 Dec;45(1):15.

20. Ahmed AE, Salih OA. Determinants of the early initiation of breastfeeding in the Kingdom of Saudi Arabia. International breastfeeding journal. 2019 Dec;14(1):13.

21. Nisa J, Salimo H, Budihastuti UR. The Effect of SocioDemographic and Obstetric Factors on Early Initiation of Breastfeeding in Tegal District, Central Java. Journal of Maternal and Child Health. 2017 Jun 19;2(2):89-99.

22. Specht IO, Rohde JF, Olsen NJ, Heitmann BL. Eating behavior and dietary intake in obesity prone normal weight children may be related to duration of exclusive breastfeeding. Revue d'Épidémiologie et de Santé Publique. 2018 Jul 1;66:S233-4.

23. Robinson H, Buccini G, Curry L, Perez?Escamilla R. The World Health Organization Code and exclusive breastfeeding in China, India, and Vietnam. Maternal \& child nutrition. 2019 Jan;15(1):e12685.

24. Mohamed N, Barnes J. Knowledge, attitudes and practices (Kap) regarding early childhood caries among nurses working in a low socio-economic area. Archives of Community Medicine \& Public Health. 2015 Jun $8 ; 1(1): 001-5$
25. Bührer C, Genzel-Boroviczény O, et al. Ernährungskommission der Deutschen Gesellschaft für Kinder und Jugendmedizin (DGKJ) Ernährung gesunder Säuglinge. Empfehlungen der Ernährungskommission der Deutschen Gesellschaft für Kinder- und Jugendmedizin. Monatsschr Kinderheilkd. 2014;162:527-538.

26. Osendarp SJ, Broersen B, van Liere MJ, De-Regil LM, Bahirathan L, Klassen E, Neufeld LM. Complementary feeding diets made of local foods can be optimized, but additional interventions will be needed to meet iron and zinc requirements in 6-to 23 -month-old children in low-and middle-income countries. Food and nutrition bulletin. 2016 Dec;37(4):544-70.

27. Habibi M., Radouani MA., Serhier Z., Doukkali L., AbkarinA., Mrabet M., Hassan A., Barkat A. Driving women?s breastfeeding and the introduction of complementary feeding in the region of Casablanca (Morocco). J Clin Gybecol Obstet. 2016; 5(4):121-128.

28. Niela-Vilén H, Melender HL, Axelin A, Löyttyniemi E, Salanterä S. Predictors of breastfeeding initiation and frequency for preterm infants in the NICU. Journal of Obstetric, Gynecologic \& Neonatal Nursing. 2016 May 1;45(3):346-58.

29. Hamze L, Mao J, Reifsnider E. Knowledge and attitudes towards breastfeeding practices: A cross-sectional survey of postnatal mothers in China. Midwifery. 2019 Jul $1 ; 74: 68-75$.

30. Vijayalakshmi P, Susheela T, Mythili D. Knowledge, attitudes, and breast feeding practices of postnatal mothers: A cross sectional survey. International journal of health sciences. 2015 Oct;9(4):364.

31. Shetty SB, Shetty K. KAP study of factors promoting breastfeeding in nursing mothers and pregnant women. Nitte University Journal of Health Science. 2013 Sep $1 ; 3(3)$.

32. Hashim TH, Mgongo M, Katanga J, Uriyo JG, Damian DJ, Stray-Pedersen B, Wandel M, Msuya SE. Predictors of appropriate breastfeeding knowledge among pregnant women in Moshi Urban, Tanzania: a cross-sectional study. International breastfeeding journal. 2016 Dec;12(1):11. 